\title{
Peer network Status and Depressive Symptoms Among Early Adolescents: Testing the Mediating Effects of Metaperception and Loneliness
}

\author{
Grzegorz Humenny $^{1} \cdot$ Paweł Grygiel $^{2} \cdot$ Roman Dolata $^{3} \cdot$ Piotr Świtaj $^{4}[$
}

Accepted: 31 December 2020 / Published online: 29 January 2021

(c) The Author(s) 2021

\begin{abstract}
Previous research shows that deficits in social relationships increase the risk of depression. This study tests the hypothesis that among early adolescents, their status in their peer network (likeability/dislikeability) will be associated with depressive symptoms but only indirectly, through the subjective perception of this status (positive/negative metaperception) and loneliness (feeling of social isolation). Data were collected using sociometric methods and self-report scales from 388 students aged 12-13. Path analysis was applied to verify the hypothesized relationships between the study variables. The findings indicate that: (1) status in the peer network and its perception affect depressive symptoms only indirectly, through loneliness; (2) depressive symptoms depend directly on loneliness alone; (3) status in the peer network does not directly translate into loneliness-its effect is mediated by metaperception; (4) the negative dimension of the peer network status indirectly affects both loneliness and depressive symptoms more strongly than the positive one. The main limitation of the research is its cross-sectional design, which precludes definite conclusions about the direction of the relationships observed. The results obtained help to clarify the complex mechanisms through which objective status in the peer network, its subjective perception and feelings of loneliness contribute to the severity of depressive symptoms among early adolescents. On the practical side, the findings highlight the importance of developing and implementing interventions targeting both the objective and subjective aspects of social relations for the prevention of depression in this age group.
\end{abstract}

Keywords Adolescence $\cdot$ Depression $\cdot$ Peer network status $\cdot$ Metaperception $\cdot$ Loneliness

\section{Introduction}

Depression is a serious mental health problem, which results from the interaction of social, psychological and biological factors and affects more than 264 million people globally (World Health Organization, 2020). It ranks among the leading causes of disability worldwide and is universally recognized as a public health priority (Ferrari et al., 2013). Typical depressive symptoms include lowered mood, loss

Piotr Świtaj

switaj@ipin.edu.pl

1 Educational Research Institute, Warsaw, Poland

2 Institute of Education, Jagiellonian University, Cracow, Poland

3 Faculty of Education, University of Warsaw, Warsaw, Poland

4 First Department of Psychiatry, Institute of Psychiatry and Neurology, Sobieskiego 9, 02-957 Warsaw, Poland of interest and enjoyment, and reduced energy leading to fatigue and diminished activity. Also common are anxiety, irritability, ideas of guilt and unworthiness, disturbed attention and concentration, problems with sleep and appetite, and suicidal ideation (World Health Organization, 1992). Depression can occur at any age and is common among adolescents. A one-year prevalence of unipolar depressive disorder in adolescence is estimated at 4-7\% (Costello et al., 2002). Youth depression is associated with a range of negative long-term functional and clinical outcomes, such as school difficulties, unemployment, impaired interpersonal relationships, psychoactive substance abuse, suicidal behavior, or physical health problems (Thapar, Collishaw, Pine, $\&$ Thapar, 2012). As a consequence, it generates substantial costs to society (Bodden, Stikkelbroek, \& Dirksen, 2018).

The pathogenesis and underlying mechanisms that lead to the development of depression in adolescence are obviously complex, but there is some evidence that psychosocial factors, including interpersonal relationships, are particularly 
relevant in this period of life (Newton, Docter, Reddin, Merlin, \& Hiller,2010; Thapar et al., 2012). Their importance at this age lies primarily in the fact that adolescents tend to define themselves and formulate their identity in terms of social relationships, experience a growing need for intimacy, and are increasingly preoccupied with their peer status (Heinrich \& Gullone, 2006; Lasgaard, Goossens, \& Elklit, 2011), defined as "the extent to which children are accepted versus rejected by their peers" (Vandell \& Hembree, 1994, p. 461).

Various aspects of the social relations of adolescents have been studied as risk factors for depression, including interpersonal conflicts, unpopularity in the peer group, social withdrawal, lack of social acceptance, lack of social support, or lack of friends (Newton et al., 2010). Among these types of factors loneliness seems to play a prominent role. Research indicates that loneliness is experienced by a substantial proportion of school children (Grygiel, Humenny, \& Rębisz, 2019), and it has been consistently identified as a significant predictor of depression across various samples and age groups (Duke, 2017; Erzen \& Çikrikci, 2018; Solmi et al., 2020).

Similar to depression, loneliness is a common condition and a major public health concern (Cacioppo \& Cacioppo, 2018). It is estimated that about 30 million European adults frequently feel lonely (European Commission, 2018). The prevalence of loneliness among adolescents is probably even greater (Heinrich \& Gullone, 2006). Loneliness is basically an unpleasant and stressful emotional state imbued with sadness and anxiety, the sources of which lie in the disparity between the expected and perceived state of an individual's interpersonal relationships (Asher \& Weeks, 2013).

The conceptual association between depression and loneliness has long been a matter of intense debate. It has been noted that although both share some common causes and features, loneliness involves appraisals of one's social connections, whereas depression is more general and involves appraisals across multiple life domains (Heinrich \& Gullone, 2006). A review of empirical studies regarding the relationship between loneliness and depression has shown that these two are in fact closely related but separate phenomena (Cacioppo \& Hawkley, 2009a; Heinrich \& Gullone, 2006). The results of some longitudinal studies carried out on adolescents and college students populations suggest that while loneliness and depression are mutually dependent in time, the impact of the sense of loneliness on depressive symptoms is greater (Vanhalst, Klimstra, et al., 2012) and more stable (Vanhalst, Luyckx, Teppers, \& Goossens, 2012) than that of depression on loneliness.

Adolescence is considered to be a critical period in the study of the occurrence of depressive symptoms and loneliness and the relationships between them (Vanhalst, Klimstra, et al., 2012). This is mainly because it has been demonstrated that both depression (Thapar et al., 2012) and loneliness (Heinrich \& Gullone, 2006) in adolescence may predict social maladjustment and ill health in adult life. Taking also into consideration the fact that the risk for loneliness peaks at this age (Heinrich \& Gullone, 2006), it becomes clear that moving out of adolescence without resolving these two interrelated psychosocial problems may have severe and far-reaching negative consequences for the lives of affected individuals.

It needs to be emphasized that as a negative feeling (Danneel et al., 2019), emotional difficulty (Matthews et al., 2016) and internalizing problem (Blossom \& Apsche, 2013), loneliness is distinct not only from depression, but also from objective social isolation (de Jong Gierveld, van Tilburg, \& Dykstra, 2006). This is confirmed by the relatively low level of correlation between loneliness and actual peer status (i.e., social positions among their peers: see Cillessen \& Bellmore, 2011; Newcomb \& Bukowski, 1983), at best reaching the value of 0.4 (c.f. Jobe-Shields, Cohen, \& Parra, 2011; London, Downey, Bonica, \& Paltin, 2007; Parker \& Asher, 1993; Pedersen, Vitaro, Barker, \& Borge, 2007; Woodhouse, Dykas, \& Cassidy, 2012).

However, this weak correlation may be partly due to the fact that social network analyses traditionally focused on relationships with a positive meaning (e.g., liking), and largely ignored a negative aspect of social ties (e.g., disliking) (Veenstra, Dijkstra, Steglich, \& Van Zalk,2013). Previous research indicates that the degree, to which a child is liked, is not simply the opposite of the degree to which a child is disliked. Rather, "liked" and "disliked" scores represent different dimensions of network position (Bukowski, Sippola, Hoza, \& Newcomb, 2000). Where correlations between "liked" and "disliked" scores have been reported, these correlations were at most moderate, among adolescents ranged from -0.06 to -0.54 , with a mean value of - 0.30 (Andrei, Mancini, Mazzoni, Russo, \& Baldaro, 2015; Berger \& Dijkstra, 2013; London, Downey, Bonica, \& Paltin, 2007; Parkhurst \& Asher, 1992; Véronneau, Vitaro, Brendgen, Dishion, \& Tremblay, 2010).

Positive relationships provide adolescents with a sense of belonging in the peer group (Baumeister \& Leary, 1995), becoming - according to goal-framing theory (Lindenberg, 2008) - a main goal for the social development of preadolescence (Babarro, Stikkelbroek, \& Dirksen, 2016). In addition, peer acceptance facilitates obtaining social support (Wentzel, Battle, Russell, \& Looney, 2010), helps to eliminate the harmful effects of stressful experiences (Cohen, 1992), improves adolescents' self-esteem (Birkeland, Breivik, \& Wold, 2014) and thus reduces the risk of psychosocial problems (Mellor, Stokes, Firth, Hayashi, \& Cummins, 2008).

In contrast, peer dislike reflects not only lack of acceptance, but also negative judgments by others, and may indicate the presence of affective conflict, antagonism, 
antipathy, animosity and active social rejection (Card, 2010; Duffy, Gardner, \& Zimmer-Gembeck, 2020). Negative interactions elicit psychological stress and in turn increase the risk of internalizing problems (Cohen, 1992), including loneliness (van Roekel et al., 2015) and depression (Cole, Nolen-Hoeksema, Girgus, \& Paul, 2006).

Although both liking and disliking are linked to internalizing problems (Sentse, Lindenberg, Omvlee, Ormel, \& Veenstra, 2010), one can expect that the effect of negative relationships outweighs the effect of positive relationships. Earlier studies-in line with the concept of positive-negative asymmetry (Anderson, 1965; Rozin \& Royzman, 2001)—consistently show that negative information is more intensely processed and contributes more strongly to the final individual perceptions and social judgments than positive information (Baumeister, Bratslavsky, Finkenauer, \& Vohs, 2001). Generally, negative events are stronger determinants of mood and affect than positive events (Taylor, 1991).

This negativity bias effect can be also expected in the context of network position and loneliness (Cacioppo \& Hawkley, 2009b). The research results demonstrate that loneliness is related to stronger expectations of and motivations to avoid bad social outcomes and weaker expectations of and motivations to achieve good social outcomes (Gable, 2006). Lonely adolescents are characterized by hypersensitivity to social exclusion (Vanhalst, Gibb, \& Prinstein, 2015). Behavioral studies suggest that lonely individuals, compared to non-lonely ones, are characterized by a greater interference effect in response to negative social words but comparable (and smaller) interference effects to positive social words (Egidi, Shintel, Nusbaum, \& Cacioppo, 2008). Similar conclusions have also been reached on the basis of studies using functional magnetic resonance imaging (fMRI) (Cacioppo, Balogh, $\&$ Cacioppo, 2015) and eye tracking research (Lodder, Scholte, Goossens, Engels, \& Verhagen, 2016).

It comes as a surprise that, despite a growing interest in the topic of negative networks (Chang, 2015), only a small number of studies have explored the relationship between status in both positive and negative social networks and loneliness (Cassidy \& Asher, 1992; Grygiel et al. 2019; Jobe-Shields et al., 2011; London et al., 2007). Importantly, none of them investigated the "pure" effect of the two network dimensions on loneliness, i.e., the relation between status in positive social networks and loneliness after controlling for the effect of a negative network position (and vice versa). It is therefore yet to be verified whether a position in a negative network (associated with disliking by peers) has a stronger effect on loneliness than a position in positive one (related to liking). Perhaps including status in both positive and negative networks in the model will be useful in explaining the larger part of the variation in loneliness.

A relatively low correlation between loneliness and peer network position may also result from the fact that the feeling of loneliness is formed by comparing social expectations with self-perceived rather than actual peer network status. This is in line with the interactionist perspective positing that people's behavior is determined to a larger degree by their subjective construction of reality (definition of the situation) than by a simple identification and representation of an objective reality (Stebbins, 2008). According to this concept, the situation in which the individual operates shall be defined as those components of the objective situation which are seen by the actor.

Peer network status has an objectified character (the number of sociometric choices in the group) (Vanhalst, Luyckx, Scholte, Engels, \& Goossens, 2013), whereas metaperception is "a person's sense of place within a hierarchy, which may or may not agree with objective status" (Sweeting, West, Young, \& Kelly, 2011, p. 493), or "an individual's view of how he or she is seen by others" (Bellmore \& Cillessen, 2003, p. 2017). At the same time, metaperception clearly differs from loneliness, the essence of which lies in the mismatch between the desired and perceived state of one's interpersonal relationships.

Metaperception may be (more or less) biased (Campbell $\&$ Fehr, 1990). If this cognitive bias is not random and is associated not only with age or cognitive development but also with emotional disposition, it can be predicted that the metaperception will be more closely related to loneliness than the actual position in the network. In fact, some recent studies indicate that metaperception bias is not random (Portillo \& Fernández-Baena, 2019) and that it is more strongly linked to loneliness than to network status (Cillessen \& Bellmore, 1999; Putarek \& Keresteš, 2016; Vanhalst et al., 2013). There is, then, empirical evidence supporting the assumption that metaperception can play the role of a mediator between peer network position and loneliness. To the best of the authors' knowledge, there is only one study that has explicitly tested such a hypothesis (Ladd \& Troop-Gordon, 2003).

We have already mentioned that network status is related not only to loneliness, but also to depression. This is only true if the analysis model does not include loneliness. The few existing studies on the relationships between depression, loneliness and network status demonstrate that when loneliness is statistically controlled for, the impact of network position measures on depression either weakens (Matthews et al., 2016) or becomes statistically nonsignificant (Boivin, Hymel, \& Bukowski, 1995). Thus, in the social context, depression is not merely a reaction to the objective social situation (Verhagen, Lodder, \& Baumeister, 2018), but above all to loneliness. Hence, there is evidence that the 
relationships between depression and network status may be mediated by loneliness.

The confirmation that depressive symptoms are primarily related to loneliness, and only indirectly to (positive or negative) network status, would seem to indicate that effective treatments and interventions for reducing depression should focus more on the correction of the maladaptive social cognition, the most effective method for reducing loneliness (Masi, Chen, Hawkley, \& Cacioppo, 2011), rather than on influencing actual network position, which is relatively stable and resistant to change and requires the participation of peers.

\section{Research Problems/Hypotheses}

The goal of the study was to examine the associationsthrough the sequential model-between statuses in positive and negative peer networks, the metaperception of these statuses, and loneliness and depressive symptoms during early adolescence. We assume that position in the peer networks will be connected with depressive symptoms only indirectly, through a sequence of mediators: metaperception mediates between the actual network position and loneliness, and loneliness mediates between metaperception and depressive symptoms.

Therefore, our first hypothesis (H1) is that the only factor directly related to depressive symptoms is loneliness, and the second hypothesis $(\mathrm{H} 2)$ is that status in the peer network will be only indirectly related to depressive symptoms through metaperception and loneliness.

At the same time, taking into consideration the fact that both depressive symptoms and loneliness are more sensitive to negative information received from the social environment, we assume that both will be more strongly related to the negative than to the positive aspect of peer network. Our third hypothesis $(\mathrm{H} 3)$ therefore predicts that negative aspects of peer network (disliking and negative metaperception) will be more strongly related than positive aspects (liking and positive metaperception) to depressive symptoms.

\section{Methods}

\section{Participants and Procedures}

Participants were 388 Caucasian adolescents (51\% girls) from 32 classes of 10 primary schools located in two Polish regions (south-eastern and middle-western), both in rural (53\% of participants) and urban areas. The sites were selected to cover both large and small schools from rural, suburban, urban and metropolitan areas. The aim was to diversify the respondents. The written consent of students and parents was obtained before the survey. Research was conducted among pupils in grades $5(35 \%)$ and $6(65 \%)$. According to the research criteria, the survey was conducted in classes where the level of consent was at least $60 \%$. A participation rate of $60 \%$, in conjunction with the procedure of unlimited nominations, provides a stable estimation of status in peer group (Cillessen, 2009). The surveys were carried out even if, on the day of the survey, not all students who gave their consent were present at the school. Response rates for classes ranged from 31 to $92 \%$, $M=61 \%$ (see: Table 5 in Appendix). The mean number of pupils in a class was $12.10(\mathrm{SD}=3.42 ; \min =8, \max =20)$, and the mean age of our respondents was $12.33(\mathrm{SD}=0.75)$ - in grade $5 M=11.69,(\mathrm{SD}=0.52)$, and $M=12.66,(\mathrm{SD}=0.63)$ in grade 6 . The presented study had a cross-sectional character.

Data were collected at the end of May and beginning of June 2017 using the computer-assisted web interview (CAWI) technique in the form of the completion of an online questionnaire on a computer/laptop by each student (in the presence of a trained interviewer/instructor). Participants did not receive any payment. The questionnaire was prepared in the students' native language, i.e., Polish. In the case of network measures, each child chose their peers from a predefined list displayed on a computer monitor containing all the classmates for whom consent to participate in the study was obtained, except the respondent him or herself.

The use of CAWI allowed for (a) elimination of the problem of missing data, (b) reduction of errors related to sociometric measurement (e.g. indicating people from outside of the surveyed community) by enabling respondents to make choices from a predefined list of students. Recent analyses (see van den Berg \& Gommans, 2017) indicate that peer-based, computer/laptop research techniques, in which children choose their peers from a predefined list, on the one hand engage the respondents more than the classic pen-and-paper technique, and on the other require less effort, making the whole process more efficient.

Since the study involved a particularly vulnerable population of early adolescents and concerned the sensitive subject of peer relations (including network status based on peer nominations), careful measures were taken to protect the participants from the risk of victimization. The process of data collection took place under the supervision of teachers. Students were also instructed not to discuss the study with their classmates. However, it should be noted that previous research regarding the harmful effects of participation in the nomination procedure on behaviors and relations among peers has not revealed any (Bell-Dolan, Foster, \& Sikora, 1989; Hayvren \& Hymel, 1984; Iverson \& Iverson, 1998). 
Table 1 The exact wording of the questions used in the sociometric nominations procedure

\begin{tabular}{|c|c|c|c|}
\hline Structure & Abbreviation & Question & Indicator \\
\hline Likeability & Like & $\begin{array}{l}\text { Mark people from your class that you like most, with whom you would like to spend most } \\
\text { time }\end{array}$ & In-degree \\
\hline Unlikeability & DisLike & $\begin{array}{l}\text { Mark people from your class that you dislike most, with whom you would like to spend } \\
\text { least time }\end{array}$ & In-degree \\
\hline Positive metaperception & PosMet & $\begin{array}{l}\text { Who do you think likes you most in your class? Who would want to spend most time with } \\
\text { you? }\end{array}$ & Out-degree \\
\hline Negative metaperception & NegMet & $\begin{array}{l}\text { Who do you think likes you least in your class? Who would want to spend least time with } \\
\text { you? }\end{array}$ & Out-degree \\
\hline
\end{tabular}

\section{Measures}

\section{Major Depression-The Revised Child Anxiety and Depression Scale (RCADS-MD)}

The RCADS is a self-report questionnaire assessing anxiety and depressive symptoms among children and adolescents, based on the DSM-IV criteria (American Psychiatric Association, 1998). This measure is composed of six subscales: social phobia (9 items), panic disorder (9 items), separation anxiety ( 7 items), generalized anxiety (6 items), obsessive-compulsive disorder ( 6 items) and major depression (10 items). The RCADS demonstrated reliability and convergent validity with existing measures of childhood anxiety and anxiety disorders (Chorpita, Yim, Moffitt, Umemoto, \& Francis, 2000; Chorpita, Moffitt, \& Gray, 2005). The RCADS requires respondents to rate how often each item applies to them. Items have to be scored on a 4-point scale with $0=$ never, $1=$ sometimes, $2=$ often, and $3=$ always. In the present study, the major depression subscale (RCADSMD) was utilized (example items: "I feel sad or empty", "I am tired a lot"). More depressive symptoms are indicated by a higher total score on this subscale. Research on the Polish version of RCADS (Skoczeń, Rogoza, Rogoza, Ebesutani, $\&$ Chorpita, 2019) indicates that it is characterized by structural and construct validity, reliability and stability among children and adolescents aged 8 to 14 . In our data Cronbach's $\alpha$ was 0.77 .

\section{Loneliness—The De Jong Gierveld Loneliness Scale (DJGLS)}

The DJGLS (de Jong Gierveld \& Kamphuls, 1985) consists of 11 items (examples: "I often feel rejected", "There are enough people I feel close to"), to which interviewees respond using a 4-point scale ranging from 1 (yes!) to 4 (no!). The scale was designed as a unidimensional instrument to study a generalized feeling of loneliness rather than to assess different types of it (de Jong Gierveld \& Kamphuls, 1985). More recent factor analyses confirm that the DJGLS is essentially (Stout, 1987) unidimensional (Grygiel, Humenny, Rębisz, Świtaj, \& Sikorska-Grygiel, 2013, cf. e.g., 2019; Penning, Liu, \& Chou, 2014). A higher total score indicates more severe loneliness. The scale is reliable and valid (de Jong Gierveld \& van Tilburg, 1999; Dykstra \& de Jong Gierveld, 2004; Grygiel et al., 2013). Previous research based on a large, representative sample of Polish fifth-grade pupils (Grygiel et al., 2019) demonstrates that the Polish adaptation of the DJGLS is essentially unidimensional, reliable, valid and stable over time. In our data, the Cronbach's $\alpha$ for this measure was 0.90 .

\section{Network Measures}

Network status was identified by the standard sociometric procedure developed by Coie, Dodge and Coppotelli (1982). Students were asked to nominate an unlimited number of classmates (irrespective of gender). The most recent studies (Cillessen \& Marks, 2017; Gommans \& Cillessen, 2015) indicate that unlimited nominations, compared to limited nominations, allow for greater stability and reliability of sociometric measurement, especially for questions about network status. These nominations were made in four categories: likeability (further in this paper referred to as Like), unlikeability (DisLike), positive metaperception (PosMet) and negative metaperception (NegMet). The exact wording of the questions is presented in Table 1. Students could choose from all the members of the class, but only those for whom consent to participate in the survey was collected were on the list. The others could be written in the previously prepared questionnaire fields themselves.

In the analyses, we used the in-degree coefficient for liking and disliking and out-degree coefficient for positive and negative metaperception. In-degree centrality (Freeman, 1978) is given as a ratio of the sum of nominations received by children to the number of all possible nominations that could be received.

$$
C_{\text {in }}^{D}\left(p_{k}\right)=\frac{\sum_{i=1}^{n} a\left(p_{i}, p_{k}\right)}{n-1}
$$


Fig. 1 Example of calculation of in-degree and outdegree measures. Note Panel A-assumed network; Panel $\mathrm{B}$-adjacency matrix of the network; Panel C-the number of received and given nominations and the values of in-degree and out-degree measures for students in the network

Example of calculation of indegree and outdegree measures.

A

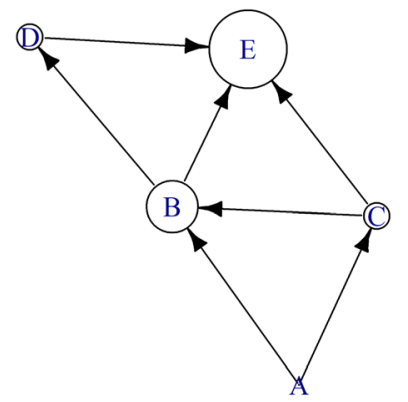

B

\begin{tabular}{c|ccccc} 
& $\mathrm{A}$ & $\mathrm{B}$ & $\mathrm{C}$ & $\mathrm{D}$ & $\mathrm{E}$ \\
\hline $\mathrm{A}$ & 0 & 1 & 1 & 0 & 0 \\
$\mathrm{~B}$ & 0 & 0 & 0 & 1 & 1 \\
$\mathrm{C}$ & 0 & 1 & 0 & 0 & 1 \\
$\mathrm{D}$ & 0 & 0 & 0 & 0 & 1 \\
$\mathrm{E}$ & 0 & 0 & 0 & 0 & 0
\end{tabular}

C

\begin{tabular}{c|cccc} 
& \multicolumn{2}{|c}{ Number of nominations } & & \\
& Received & Given & Indegree & Outdegree \\
\hline A & 0 & 2 & 0.00 & 0.50 \\
B & 2 & 2 & 0.50 & 0.50 \\
C & 1 & 2 & 0.25 & 0.50 \\
D & 1 & 1 & 0.25 & 0.25 \\
E & 3 & 0 & 0.75 & 0.00
\end{tabular}

Out-degree centrality (Freeman, 1978) is, by analogy, the ratio of the sum of nominations given by a child to the number of all peers in the class minus 1 .

$C_{\text {out }}^{D}\left(p_{i}\right)=\frac{\sum_{k=1}^{n} a\left(p_{i}, p_{k}\right)}{n-1}$

where $a\left(p_{i}, p_{k}\right)$-takes the value 1 if and only if $p_{i}$ selects $p_{k}$, in other cases 0 and $n-1$-number of members of the group to which $p_{i}$ and $p_{k}$ belong (number of people in the group minus 1).

Let us assume that we have a network like the one presented in Panel A of Fig. 1. Student A nominates students $\mathrm{B}$ and $\mathrm{C}$, but nobody nominates him/her. At the same time, student $\mathrm{E}$ does not nominate any other group member but is nominated by three peers. Panel B represents an adjacency matrix which contains the same information as the graph in Panel A. From the lines, we can read whom the group members have chosen, and from the columns who was chosen by whom. For example, student $\mathrm{C}$ selected $\mathrm{B}$ and $\mathrm{E}$ ( 1 in column $\mathrm{B}$ and column $\mathrm{E}$ of row $\mathrm{C}$ ). He himself was chosen by A ( 1 in row A of column C). Panel C shows the number of received and given nominations (column and row, respectively) and the values of in-degree and out-degree measures created by dividing the appropriate number of nominations by 4 , i.e., the number of group members minus 1 (see Fig. 1). In-degree and out-degree values range from 0 to 1 . Coefficients were calculated in the igraph package (Csardi \& Nepusz, 2006).
As a result, likeability (in-degree based on positive nominations) indicates the proportion of peers in the class who like the respondent (a higher score indicates higher network status). Unlikeability (in-degree based on negative nominations), on the other hand, is an indicator of the proportion of the respondent's class peers who do not like the respondent (a higher score indicates a lower network status). A positive metaperception (out-degree based on positive nominations) refers to the respondents' belief as to what proportion of their peers in the class like them, while a negative metaperception (out-degree based on negative nominations) reflects their belief about the proportion of their peers in the class that dislike them.

\section{The Plan of the Statistical Analyses}

For all study variables, means and standard deviations or percentages, as appropriate, were calculated. Cronbach's $\alpha$ coefficients were computed to examine the internal consistency and reliability of the scales. Bivariate associations between the constructs of interest were assessed by Pearson product-moment correlations.

The main analyses were carried out using path modeling. This is an extension of multiple regression that allows us to examine more complicated relations among the variables than multiple regression, with its single dependent variable (Streiner, 2005). Path analysis is a sequence of several regressions and possible correlations determined based on the hypotheses adopted, allowing for the simultaneous estimation of a series of partial regression coefficients (when 
Fig. 2 Path model for mediation analysis. Note DepressionMajor Depression subscale from Revised Children's Anxiety and Depression Scale (RCADS); Loneliness-de Jong Gierveld Loneliness Scale (DJGLS); PosMet-positive metaperception; NegMet—negative metaperception; Like-likeability; DisLike-unlikeability; solid lines-regression paths; dashed lines-correlation paths
Path model for mediation analysis.

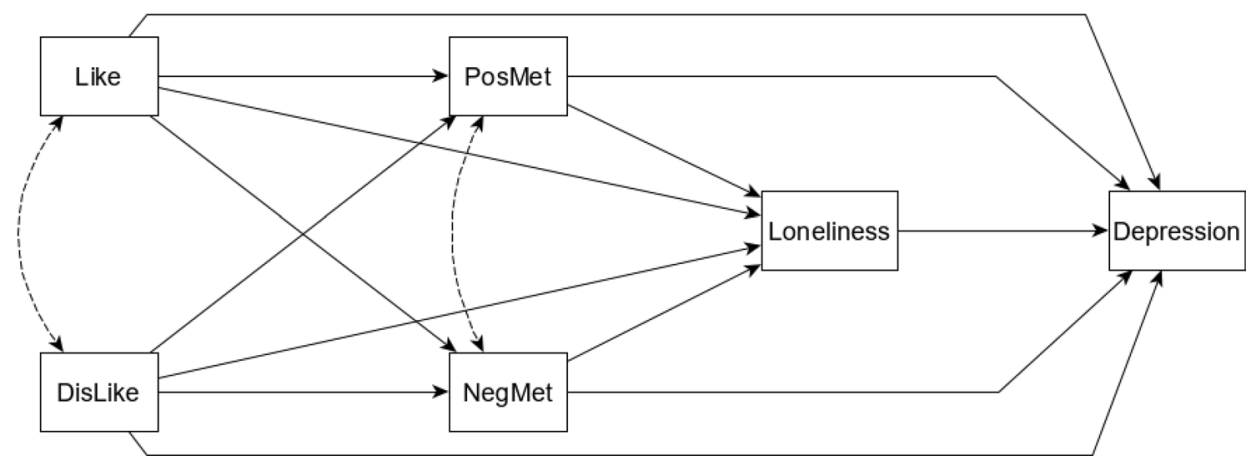

controlling all variables included in the path model). In other words, it permits the consideration of chains of association, such that variable A can influence variable B, and B in turn can affect $C$. Unlike multiple regression models, path analysis estimates not only direct, but also indirect effects of an independent variable on a dependent variable that passes through one or more mediator variables.

However, one limitation of path analysis is that it can handle only variables that are observed (Streiner, 2006). Structural equation modeling (SEM) extends path analysis by allowing the examination of relations (direct and indirect) among latent variables. Note that in SEM the relations among the latent variables reflect their relations, uncontaminated by measurement error. Unfortunately, SEM requires a much larger sample size than path analysis. According to Jackson (2003) and Kline (2011), a sample size in SEM depends on model complexity, i.e., the ratio of cases $(N)$ to the number of model parameters that require statistical estimates $(q)$. An ideal sample size-to-parameters ratio would be 20:1, and minimally 5:1. In our alternative SEM model, where the number of parameters would equal 107, the optimal sample should be 2140 and the minimal at least 535. Unfortunately, our sample was smaller $(N=388$; see Participants and Procedures). As a consequence, we used a path model.

According to the hypotheses adopted, it was assumed that: (1) the only direct predictor of depressive symptoms is loneliness; (2) the metaperception of positive and negative network status is associated with loneliness; (3) status in the peer networks (liking, disliking) is related to metaperception. It is therefore assumed that liking and disliking will be connected with loneliness and depressive symptoms only indirectly-in the case of loneliness through metaperception, and in the case of depressive symptoms through metaperception and loneliness (see Fig. 2).

\section{Software and Estimation Methods}

All analyses were carried out using the Mplus 8.2 package using maximum likelihood (ML) estimation (Muthén and
Muthén 2017). Since the analyzed data were hierarchicalchildren were nested in classes- the complex sample option in Mplus was used to avoid bias to standard errors and test statistics. Due to the use of CAWI as a data collection technique (see section Participants and Procedures), the database did not include the missing data. In all the analyses conducted, the level of statistical significance was set at 0.05 .

The bootstrapping procedure recommended by Preacher and Hayes (2008) was applied to test the significance of the indirect effects. Unlike traditional tests, such as the Sobel test (Sobel, 1982), bootstrapping does not require the assumption that the sampling distribution of the indirect effect is normal, which is difficult to meet for small research samples especially. We used 5000 bootstrap resamples to calculate the bias-corrected $95 \%$ confidence interval (CI). If the interval does not include zero, the effect is statistically significant at $p<0.05$.

\section{Results}

Means, standard deviations and correlations with confidence intervals for measures used in the study are presented in Table 2.

Standardized regression parameters from the tested path model of direct effects are shown in Table 3 . The severity of depressive symptoms depends directly only on loneliness, and the relationship is relatively strong $(\beta=0.53, \mathrm{SE}=0.05$, $p<0.01$ ), explaining as much as $28.9 \%$ of the variance in depressive symptoms.

Loneliness, on the other hand, is only directly conditioned by metaperception. Loneliness depends to a larger degree on the metaperception of status in the negative network $(\beta=0.23, \mathrm{SE}=0.07, p<0.01)$ than in the positive one $(\beta=-0.13, \mathrm{SE}=0.04, p<0.01)$. Importantly, loneliness is not affected directly either by being liked or being disliked by peers, as the effects are statistically nonsignificant. The predictors explain $12.8 \%$ of the variance in loneliness.

Interestingly, the metaperception of one's own status in the network (both positive and negative) depends only on 
Table 2 Means, standard deviations and correlations with confidence intervals
Table 3 The direct effects from the tested path model (standardized regression parameters)

\begin{tabular}{lcclllll}
\hline Variable & $M$ & SD & 1 & 2 & 3 & 4 & 5 \\
\hline 1. Like & 0.50 & 0.29 & & & & \\
2. DisLike & 0.14 & 0.16 & $-.49^{* *}$ & & & & \\
& & & {$[-.56,-.41]$} & & & \\
3. Positive & 0.30 & 0.22 & $.14^{* *}$ & $-.18^{* *}$ & & & \\
metaperception & & & {$[.04, .24]$} & {$[-.28,-.09]$} & & \\
4. Negative & 0.11 & 0.15 & $-.23^{* *}$ & $.32^{* *}$ & -.09 & \\
metaperception & & & {$[-.32,-.13]$} & {$[.23, .41]$} & {$[-.18, .01]$} & \\
5. Loneliness & 15.60 & 5.68 & $-.20^{* *}$ & $.24^{* *}$ & $-.18^{* *}$ & $.29^{* *}$ \\
& & & {$[-.29,-.10]$} & {$[.14, .33]$} & {$[-.27,-.08]$} & {$[.20, .38]$} & \\
6. Depressive symptoms & 14.93 & 4.37 & $-.13^{*}$ & .07 & -.04 & $.19^{* *}$ & $.53^{* *}$ \\
& & & {$[-.22,-.03]$} & {$[-.03, .17]$} & {$[-.14, .06]$} & {$[.09, .29]$} & {$[.45, .59]$} \\
\hline
\end{tabular}

$M$ and $S D$ are used to represent mean and standard deviation, respectively. Values in square brackets indicate the $95 \%$ confidence interval for each correlation. The confidence interval is a plausible range of population correlations that could have caused the sample correlation (Cumming 2014)

*Indicates $p<0.05$. **Indicates $p<0.01$

\begin{tabular}{lllll}
\hline & \multicolumn{2}{l}{ Direct effect } & & \\
\cline { 2 - 5 } & PosMet & NegMet & Loneliness (DJGLS) & $\begin{array}{l}\text { Depression } \\
\text { (RCADS- } \\
\text { MD) }\end{array}$ \\
& $\beta(\mathrm{SE})$ & $\beta(\mathrm{SE})$ & $\beta(\mathrm{SE})$ & $\beta(\mathrm{SE})$ \\
\hline Like & $.06(.05)$ & $-.10(.06)$ & $-.08(.06)$ & $-.07(.06)$ \\
DisLike & $-.15(.06)^{* *}$ & $.28(.08)^{* *}$ & $.10(.08)$ & $-.10(.06)$ \\
PosMet & - & - & $-.13(.04)^{* *}$ & $.05(.04)$ \\
NegMet & - & - & $.23(.07)^{* *}$ & $.06(.06)$ \\
Loneliness (DJGLS) & - & - & - & $.53(.05)^{* *}$ \\
$R$-square & .037 & .110 & .128 & .288 \\
\hline
\end{tabular}

$\beta$ estimation of standardized coefficient; SE standard error; CI confidence interval; RCADS-MD, Revised Child Anxiety and Depression Scale-Major Depression; DJGLS, de Jong Gierveld Loneliness Scale; Like likeability; DisLike unlikeability; PosMet positive metaperception; NegMet negative metaperception

${ }^{*} p<0.05,{ }^{* *} p<0.01$ the position occupied in the negative network (in the case of PozMet: $\beta=-0.15, \mathrm{SE}=0.06, p<0.01$; in the case of NegMet: $\beta=0.28, \mathrm{SE}=0.08, p<0.01)$. Liking, with statistical control of disliking, is not significantly associated either with positive $(\beta=0.06, \mathrm{SE}=0.05, p=0.22)$ or negative metaperception $(\beta=-0.10, \mathrm{SE}=0.06, p=0.10)$. Additionally, status in the positive and negative peer network explains more variance of the indicator of negative rather than positive metaperception $(11.0 \%$ vs. $3.7 \%)$.

The results presented here do not mean, however, that depressive symptoms are entirely independent of goings-on in the peer networks. Although no significant indirect effect in the case of status in the positive network has been noted, we have found two essential indirect effects in the case of the status in the negative network (see Table 4). The status in the negative network increases the intensity of depressive symptoms through the mediating effect of positive metaperception and loneliness $\left(\beta_{\mathrm{IND}}=0.01,95 \% \mathrm{CI} 0.01\right.$ and 0.02$)$ and, most of all, negative metaperception and loneliness $\left(\beta_{\text {IND }}=\right.$ $0.03,95 \%$ CI 0.01 and 0.06 ). The more disliked the person is the worse is his or her perception of the position occupied in the group (negative metaperception is more intense than positive), which increases the level of loneliness, leading to a higher intensity of depressive symptoms.

It should be noted, however, that in the case of the influence of disliking it is only the effect with sequential mediation (through metaperception and loneliness) that turns out to be statistically significant. The effect of a single mediating 
Table 4 The indirect effects from the tested path model (standardized regression parameters)

\begin{tabular}{|c|c|c|c|c|c|c|c|}
\hline \multicolumn{4}{|c|}{ Indirect effect } & & & & \multirow[t]{2}{*}{$\beta_{\mathrm{IND}}(95 \% \mathrm{CI})$} \\
\hline \multicolumn{7}{|c|}{ on Loneliness (DJGLS) } & \\
\hline Like & $\rightarrow$ & PosMet & $\rightarrow$ & Loneliness (DJGLS) & & & $-.01(-.02$ to .01$)$ \\
\hline Like & $\rightarrow$ & NegMet & $\rightarrow$ & Loneliness (DJGLS) & & & $-.02(-.06$ to .01$)$ \\
\hline DisLike & $\rightarrow$ & PosMet & $\rightarrow$ & Loneliness (DJGLS) & & & $.02(.01 \text { to } .04)^{*}$ \\
\hline DisLike & $\rightarrow$ & NegMet & $\rightarrow$ & Loneliness (DJGLS) & & & $.06(.02 \text { to } .12)^{*}$ \\
\hline \multicolumn{8}{|c|}{ on Depression (RCADS-MD) } \\
\hline Like & $\rightarrow$ & PosMet & $\rightarrow$ & & & Depression (RCADS-MD) & $.01(-.01$ to .01$)$ \\
\hline Like & $\rightarrow$ & NegMet & $\rightarrow$ & & & Depression (RCADS-MD) & $-.01(-.02$ to .01$)$ \\
\hline Like & $\rightarrow$ & & & Loneliness (DJGLS) & $\rightarrow$ & Depression (RCADS-MD) & $-.04(-.10$ to .02$)$ \\
\hline Like & $\rightarrow$ & PosMet & $\rightarrow$ & Loneliness (DJGLS) & $\rightarrow$ & Depression (RCADS-MD) & $-.01(-.01$ to .01$)$ \\
\hline Like & $\rightarrow$ & NegMet & $\rightarrow$ & Loneliness (DJGLS) & $\rightarrow$ & Depression (RCADS-MD) & $-.01(-.03$ to .01$)$ \\
\hline DisLike & $\rightarrow$ & PosMet & $\rightarrow$ & & & Depression (RCADS-MD) & $-.01(-.02$ to .01$)$ \\
\hline DisLike & $\rightarrow$ & NegMet & $\rightarrow$ & & & Depression (RCADS-MD) & $.02(-.01$ to .06$)$ \\
\hline DisLike & $\rightarrow$ & & & Loneliness (DJGLS) & $\rightarrow$ & Depression (RCADS-MD) & $.05(-.02$ to .13$)$ \\
\hline DisLike & $\rightarrow$ & PosMet & $\rightarrow$ & Loneliness (DJGLS) & $\rightarrow$ & Depression (RCADS-MD) & $.01(.01 \text { to } .02)^{*}$ \\
\hline \multirow[t]{3}{*}{ DisLike } & $\rightarrow$ & NegMet & $\rightarrow$ & Loneliness (DJGLS) & $\rightarrow$ & Depression (RCADS-MD) & $.03(.01 \text { to } .07)^{*}$ \\
\hline & & PosMet & $\rightarrow$ & Loneliness (DJGLS) & $\rightarrow$ & Depression (RCADS-MD) & $-.07(-.11$ to -.03$)$ \\
\hline & & NegMet & $\rightarrow$ & Loneliness (DJGLS) & $\rightarrow$ & Depression (RCADS-MD) & $.12(.05 \text { to } .20)^{*}$ \\
\hline
\end{tabular}

$\beta$ estimation of standardized coefficient; CI confidence interval; RCADS-MD Revised Child Anxiety and Depression Scale-Major Depression; DJGLS de Jong Gierveld Loneliness Scale; Like likeability; DisLike unlikeability; PosMet positive metaperception; NegMet negative metaperception

${ }^{*} p<0.05, * * p<0.01$

factor (loneliness alone) is nonsignificant $\left(\beta_{\mathrm{IND}}=0.05,95 \%\right.$ CI -0.02 and 0.13$){ }^{1}$

\section{Discussion}

The purpose of this study was to investigate the mechanisms through which status in the peer network affects the severity of depressive symptoms among early adolescents aged 12-13. More specifically, the path model was tested in an attempt to explain the phenomenon of depression through the mediation processes of the subject processing information from the social environment. We assumed that both depressive symptoms and loneliness would be linked to the actual state of peer relations only insofar as the stimuli from the social environment (i.e., being liked/disliked by others) would be transformed into a mental representation (meaningful interpretation) of the stimulus (Dodge, 1993).

\footnotetext{
1 The model presented above was also estimated taking into account the control variables, i.e., sex, grade, region, registered permanent residence and family socio-economic status. These variables were introduced in two ways: 1) as additional regressors of depression and 2) as regressors of all variables included in the model. Presented relations (both direct and indirect) between the variables did not change when these control variables were incorporated into the model.
}

Our results suggest that the intensity of depressive symptoms depends directly only on loneliness, whereas the objective position occupied in the peer network (liking/disliking) and its perception (positive/negative metaperception) affect depressive symptoms only indirectly through loneliness. This is a result consistent with our hypotheses (H1 an H2), indicating that it is not so much social facts or their perception (metaperception), but individuals' interpretations, such as a generalized negative assessment of the quality of their own social relationships (loneliness), that are the factors conducive to a higher severity of depressive symptoms.

Also, status in the peer network (liking/disliking) is not directly related to loneliness. Its effect is mediated by the metaperception of one's own network position. The level of loneliness depends primarily on one's beliefs about the status occupied within the networks and is only secondary to the actual place occupied in the structure. At the same time, the peer network status and its metaperception explain only $12.8 \%$ of the variance in loneliness. The vast majority (over $4 / 5$ ) of the variability in subjective isolation is not related to the sphere of peer acceptance/rejection. In fact, status in the peer network is a poor predictor of metaperception; liking explains only $3.7 \%$ of the positive and disliking $11.0 \%$ of the negative metaperception. The actually occupied network position translates only to a small extent into the ways in which adolescents perceive their position, and the perception 
is relatively weakly associated with loneliness. Generally speaking, intersubjective social phenomena are distorted, but even these inaccurate interpretations poorly differentiate loneliness and, indirectly, depressive symptoms.

The third of our hypotheses (H3) was also supported, namely that the negative aspect of peer relationships (disliking) affects (indirectly) both loneliness and depressive symptoms more strongly than the positive one (liking). This result is consistent with the tendency of early adolescents to pay selective attention to negative social cues (Bangee, Harris, Bridges, Rotenberg, \& Qualter, 2014), remember more of the negative aspects of social events (Duck et al. 1994), have difficulties diverting attention away from those cues and become more likely to behave in ways that confirm their negative expectations. Research (Ciarrochi \& Heaven, 2008) indicates that a negative cognitive style allows for the longitudinal prediction of sadness, which is the basic characteristic of both loneliness (Asher \& Weeks, 2012), and depression (Beck \& Alford, 2009). It has been found that adolescents with a negative attribution style associated with peer relationships more often report a higher level of loneliness and depression two years later, compared to subjects with a more optimistic style (Toner \& Heaven, 2005).

The findings from the present study may have important theoretical implications regarding the links between the various aspects of social relationships and loneliness among adolescents. Perhaps the not-too-strong relations between subjective isolation and the perceived state of one's peer relationships, with strong relationships between loneliness and the intensity of depressive symptoms, result from the fact that a previously activated negative attribution underlies the elevated level of loneliness (Dozois \& Beck, 2008) rather than, as is assumed by the cognitive discrepancy model of loneliness (Archibald, Bartholomew, \& Marx, 1995), from the deficit between the relationships available and individual expectations/needs (secondarily activating the negative cognitive style and increasing the severity of depressive symptoms). However, we are unable to determine the nature of the factors activating the negative cognitive style on the basis of this research. Further studies that consider a wider set of variables are needed.

It should be noted that, based on past theory and research, our model assumed that depressive symptoms are predicted (Hoffman, Cole, Martin, Tram, \& Seroczynski, 2000) by poor peer relationships, peer-relevant cognition and loneliness. The finding that generalized negative affect may be the source of loneliness and depressive symptoms leads us to the conclusion that it may be worth considering another model (an "effect model"), which assumes that depression may contribute to a failure in peer relationships (Zimmer-Gembeck,
Hunter, Waters, \& Pronk, 2009). Such a model would be justified on the basis of the previous longitudinal studies that indicate that the focus on negative stimuli and seeking negative feedback, so characteristic of depression, result in increasingly frequent withdrawals from relationships and the experiencing of a higher level of social stress (Caldwell, Rudolph, Troop-Gordon, \& Kim, 2004); the resulting depressive symptoms make people feel even more lonely (Lasgaard et al., 2011).

Our results are also congruent with the "transactional model", emphasizing bidirectional influences between social experiences, cognitions, and depression (Rudolph, 2009) or loneliness (Cacioppo, Cacioppo, \& Boomsma, 2014). Further longitudinal research is needed to confirm directional model paths and, in particular, to determine whether reciprocal relationships between model constructs exist.

As far as practical implications are concerned, our results highlight the importance of careful screening of the adolescent population for the severity of feelings of loneliness, which emerged as a factor strongly contributing to depressive symptoms. In view of the findings obtained, loneliness may have the potential to undermine the mental health, wellbeing and daily functioning of young people. Thus, there is a need to identify individuals with a high sense of loneliness and help them to resist it.

Researchers distinguish four main strategies of lonelinessreduction interventions: improving social skills, enhancing social support, increasing opportunities for social contact, and addressing maladaptive social cognition (Masi et al., 2011). Given that the analyses conducted demonstrated loose links between loneliness and objective indicators of the social relationships of adolescents, this research seems to indirectly provide further support to the findings of the metaanalysis by Masi et al. (2011), which indicate that addressing biased social cognition is the most promising way of counteracting loneliness. This is not to say that improving the interpersonal skills of adolescents, providing them with social support or increasing their opportunities for social contacts are unimportant. The only meta-analysis focusing specifically on methods for alleviating loneliness in young people (Eccles \& Qualter, 2020) demonstrated that interventions could moderately reduce loneliness. However, it did not confirm that one type of intervention was significantly more effective than others. The authors conclude that researchers, policymakers and practitioners should be aware, first, that loneliness is a modifiable factor and, second, that any loneliness intervention should be tailored to an individual's current needs and no "one size fits all" intervention should be expected. 
The same refers to the prevention of depression among adolescents. It has been established that a targeted and indicated mitigation strategy is effective in preventing the development of depression in this age group whereas universal prevention is not (Thapar et al., 2012). Our study suggests that building resilience to depression in young people requires interventions addressing both the objective and subjective features of their interpersonal relationships.

The findings from this research must be interpreted in the light of several methodological limitations. First, the data are cross-sectional, which precludes any definite inferences about the direction of the relationships between variables. Next, it should be considered that the sample was a targeted one (which is typical for studies using sociometric nominations), comprised of Polish students, and therefore the findings may not be generalized to preadolescent youths in other countries and contexts. The response rate in some classes was quite low, thus potentially causing some problems with the estimation of unbiased peer network measures and the generalizability of the results.

It is also possible that the reason for the relations between loneliness/depressive symptoms and peer relations being not so strong may be rooted in the fact that the study does not include other important aspects of interpersonal relations. After all, this study used only the measures of liking/disliking. Yet other studies show an additive influence that other aspects of peer relations have on loneliness, with (un)popularity leading the way (Engels et al., 2017).

Furthermore, our analyses did not include the qualitative aspect of peer relations. Research demonstrates that loneliness is sensitive not only to the quantitative aspect of peer relations ("how many people like or dislike me"), but also the quality of interactions, primarily of friendships (Nangle, Erdley, Newman, Mason, \& Carpenter, 2003).

A fuller picture of these determinants would be given by taking into consideration relations with parents. Some studies show that the support received at home from parents in the period of early adolescence is still a better predictor of loneliness than the support received from peers (Cavanaugh $\&$ Buehler, 2016) and that it can lower the risk of depression (Yap et al., 2017).

In our study, both depressive symptoms and loneliness were based on self-report. Thus, the strength of mediation may have been overestimated because of the common method variance between the mediator and the outcome (Zimmer-Gembeck, Hunter, \& Pronk,2007). Indeed, research experience suggests that measures based on self-assessment may be more strongly linked to self-reported rather than clinician-rated depression (Świtaj, Grygiel, Chrostek, Wciórka, \& Anczewska, 2018). Subsequent research should consider additional sources of information for depression, including the severity of depressive symptoms as assessed by a clinician.

In this study, the DJGLS scale was used as a measure of loneliness. The DJGLS measures loneliness without referring to the school/class context. It assesses the overall feeling of loneliness (Grygiel et al., 2019), based also on nonschool interpersonal relationships, for example, relationships with parents. So, in our study the relation between peer network status and loneliness may be somewhat biased. In subsequent studies, other measures of loneliness should be used, e.g., the Loneliness and Social Dissatisfaction Questionnaire-LSDS (Asher \& Wheeler, 1985), which directly refers to peer relations at school.

Finally, it should be noted the level of depressive symptoms in the recruited sample was rather low. Namely, the mean score on the RCADS-MD equaled 0.49 (with a possible range of 0-3) and was even slightly lower than that found (i.e., 0.70) in the validation study of the Polish version of the RCADS (Skoczeń et al., 2019), which was conducted on a large community sample of 501 children and adolescents. This could have affected the magnitude of the associations between depressive symptoms and other variables of interest.

Notwithstanding these limitations, we believe that our research helps to clarify the mechanisms through which status in a peer network, its subjective perception (metaperception) and feelings of loneliness contribute to the severity of depressive symptoms among early adolescents. Most notably, our results reinforce the significance of loneliness, which turned out to be a factor directly and most strongly related to higher levels of depressive symptoms. Furthermore, the findings obtained deliver noteworthy insights into the nature of adolescent loneliness. Namely, given its weak associations with objective position in the peer network, loneliness appears to be more a psychological than a social phenomenon.

\section{Appendix}

See Table 5. 
Table 5 Response rate by classes

\begin{tabular}{|c|c|c|c|c|c|c|c|}
\hline Class & $\begin{array}{l}\text { Response rate } \\
(\%)\end{array}$ & Class & $\begin{array}{l}\text { Response rate } \\
(\%)\end{array}$ & Class & $\begin{array}{l}\text { Response rate } \\
(\%)\end{array}$ & Class & $\begin{array}{l}\text { Response } \\
\text { rate }(\%)\end{array}$ \\
\hline A5a & 40.0 & C6b & 88.2 & G6a & 42.9 & K6b & 75.0 \\
\hline $\mathrm{A} 5 \mathrm{e}$ & 65.0 & F5b & 90.5 & G6b & 65.2 & L5a & 57.9 \\
\hline A6b & 34.6 & F6a & 76.2 & $\mathrm{H} 5 \mathrm{a}$ & 59.1 & L5b & 66.7 \\
\hline A6d & 31.0 & F6b & 38.1 & H6a & 59.3 & L6a & 65.0 \\
\hline A6e & 34.5 & F6c & 76.2 & $\mathrm{H} 6 \mathrm{~b}$ & 74.1 & L6b & 57.9 \\
\hline A6h & 39.1 & F6d & 90.5 & I5a & 54.2 & L6c & 42.9 \\
\hline $\mathrm{C} 5 \mathrm{~b}$ & 60.0 & G5a & 75.0 & J6a & 60.0 & L6d & 61.9 \\
\hline C6a & 66.7 & G5b & 47.6 & K5a & 92.3 & M6a & 64.3 \\
\hline
\end{tabular}

Funding This work was supported by Faculty of Philosophy of the Jagiellonian University decision number 221.3110.3.2016 and by a grant from The Polish National Science Centre $(\mathrm{NCN})$, project number 2017/27/B/HS6/00850.

\section{Compliance with Ethical Standards}

Conflict of interest The authors declare that they have no conflict of interest.

Ethics Approval All study procedures were conducted in accordance with the ethical standards of the institutional and/or national research committee and with the 1964 Helsinki declaration and its later amendments or comparable ethical standards.

Consent to Participate Informed consent was obtained from all individual students included in the study and from their parents.

Open Access This article is licensed under a Creative Commons Attribution 4.0 International License, which permits use, sharing, adaptation, distribution and reproduction in any medium or format, as long as you give appropriate credit to the original author(s) and the source, provide a link to the Creative Commons licence, and indicate if changes were made. The images or other third party material in this article are included in the article's Creative Commons licence, unless indicated otherwise in a credit line to the material. If material is not included in the article's Creative Commons licence and your intended use is not permitted by statutory regulation or exceeds the permitted use, you will need to obtain permission directly from the copyright holder. To view a copy of this licence, visit http://creativecommons.org/licenses/by/4.0/.

\section{References}

Anderson, N. H. (1965). Averaging versus adding as a stimuluscombination rule in impression formation. Journal of Experimental Psychology, 70 (4), 394-400. https://doi.org/10.1037/ h0022280

Andrei, F., Mancini, G., Mazzoni, E., Russo, P. M., \& Baldaro, B. (2015). Social status and its link with personality dimensions, trait emotional intelligence, and scholastic achievement in children and early adolescents. Learning and Individual Differences, 42, 97-105. https://doi.org/10.1016/j.lindif.2015.07.014

Archibald, F. S., Bartholomew, K., \& Marx, R. (1995). Loneliness in early adolescence: A test of the cognitive discrepancy model of loneliness. Personality and Social Psychology Bulletin, 21(3), 296-301. https://doi.org/10.1177/0146167295213010
Asher, S. R., \& Weeks, M. S. (2012). Social relationships, academic engagement, and well-being in college: Findings from the Duke social relationships project. Duke University. http://sites.duke. edu/dsrp/files/2012/09/DSRP-Report-FINAL-with-Date.pdf. Accessed 2 September 2015.

Asher, S. R., \& Weeks, M. S. (2013). Loneliness and belongingness in the college years. In R. J. Coplan, \& J. C. Bowker (Eds.), The handbook of solitude (pp. 283-301). Hoboken, NJ: Wiley.

Asher, S. R., \& Wheeler, V. A. (1985). Children's loneliness: A comparison of rejected and neglected peer status. Journal of Consulting and Clinical Psychology, 53(4), 500-505. https:// doi.org/10.1037/0022-006X.53.4.500

American Psychiatric Association (Ed.). (1998). Diagnostic and statistical manual of mental disorders: DSM-IV ; includes ICD9-CM codes effective 1. Oct. 96 (4. ed., 7. print.). Washington, DC.

Babarro, J. M., Diaz-Aguado, M. J., Martinez Arias, R., \& Steglich, C. (2016). Power structure in the peer group: The role of classroom cohesion and hierarchy in peer acceptance and rejection of victimized and aggressive students. The Journal of Early Adolescence. https://doi.org/10.1177/0272431616648451.

Bangee, M., Harris, R. A., Bridges, N., Rotenberg, K. J., \& Qualter, P. (2014). Loneliness and attention to social threat in young adults: Findings from an eye tracker study. Personality and Individual Differences, 63, 16-23. https://doi.org/10.1016/j. paid.2014.01.039.

Baumeister, R. F., Bratslavsky, E., Finkenauer, C., \& Vohs, K. D. (2001) Bad is stronger than good. Review of General Psychology, 5(4), 323-370. https://doi.org/10.1037/1089-2680.5.4.323.

Baumeister, R. F., \& Leary, M. R. (1995). The need to belong: Desire for interpersonal attachments as a fundamental human motivation. Psychological Bulletin, 117(3), 497-529.

Beck, A. T., \& Alford, B. A. (2009). Depression: Causes and treatment (2nd ed.). Philadelphia: University of Pennsylvania Press.

Bell-Dolan, D. J., Foster, S. L., \& Sikora, D. M. (1989). Effects of sociometric testing on children's behavior and loneliness in school. Developmental Psychology, 25(2), 306-311.

Bellmore, A. D., \& Cillessen, A. H. N. (2003). Children's meta-perceptions and meta-accuracy of acceptance and rejection by samesex and other-sex peers. Personal Relationships, 10(2), 217-234. https://doi.org/10.1111/1475-6811.00047.

Berger, C., \& Dijkstra, J. K. (2013). Competition, envy, or snobbism? How popularity and friendships shape antipathy networks of adolescents. Journal of Research on Adolescence, 23(3), 586-595. https://doi.org/10.1111/jora.12048.

Birkeland, M. S., Breivik, K., \& Wold, B. (2014) Peer acceptance protects global self-esteem from negative effects of low closeness to parents during adolescence and early adulthood. Journal of 
Youth and Adolescence, 43(1), 70-80. https://doi.org/10.1007/ s10964-013-9929-1.

Blossom, P., \& Apsche, J. (2013). Effects of loneliness on human development. International Journal of Behavioral Consultation and Therapy, 7(4), 28-29. https://doi.org/10.1037/h0100963.

Bodden, D. H. M., Stikkelbroek, Y., \& Dirksen, C. D. (2018). Societal burden of adolescent depression, an overview and cost-of-illness study. Journal of Affective Disorders, 241, 256-262. https://doi. org/10.1016/j.jad.2018.06.015.

Boivin, M., Hymel, S., \& Bukowski, W. M. (1995). The roles of social withdrawal, peer rejection, and victimization by peers in predicting loneliness and depressed mood in childhood. Development and Psychopathology, 7(04), 765. https://doi.org/10.1017/S0954 579400006830.

Bukowski, W. M., Sippola, L., Hoza, B., \& Newcomb, A. F. (2000). Pages from a sociometric notebook: An analysis of nomination and rating scale measures of acceptance, rejection, and social preference. In A. H. N. Cillessen \& W. M. Bukowski (Eds.), Recent advances in the measurement of acceptance and rejection in the peer system (pp. 11-26). San Francisco: Jossey-Bass.

Cacioppo, J. T., \& Cacioppo, S. (2018). The growing problem of loneliness. The Lancet, 391(10119), 426. https://doi.org/10.1016/ S0140-6736(18)30142-9.

Cacioppo, J. T., Cacioppo, S., \& Boomsma, D. I. (2014). Evolutionary mechanisms for loneliness. Cognition and Emotion, 28(1), 3-21. https://doi.org/10.1080/02699931.2013.837379.

Cacioppo, J. T., \& Hawkley, L. C. (2009). Loneliness. In M. R. Leary, \& R. H. Hoyle (Eds.), Handbook of individual differences in social behavior (pp. 227-240). New York: Guilford Press.

Cacioppo, J. T., \& Hawkley, L. C. (2009). Perceived social isolation and cognition. Trends in Cognitive Sciences, 13(10), 447-454. https://doi.org/10.1016/j.tics.2009.06.005.

Cacioppo, S., Balogh, S., \& Cacioppo, J. T. (2015) Implicit attention to negative social, in contrast to nonsocial, words in the Stroop task differs between individuals high and low in loneliness: Evidence from event-related brain microstates. Cortex, 70, 213-233. https://doi.org/10.1016/j.cortex.2015.05.032.

Caldwell, M. S., Rudolph, K. D, Troop-Gordon, W., \& Kim, D.-Y. (2004). Reciprocal influences among relational self-views, social disengagement, and peer stress during early adolescence. Child Development, 75(4), 1140-1154. https://doi.org/10.111 1/j.1467-8624.2004.00730.x.

Campbell, J. D., \& Fehr, B. (1990). Self-esteem and perceptions of conveyed impressions: Is negative affectivity associated with greater realism? Journal of Personality and Social Psychology, 58(1), 122-133. https://doi.org/10.1037/0022-3514.58.1.122.

Card, N. A. (2010). Antipathetic relationships in child and adolescent development: A meta-analytic review and recommendations for an emerging area of study. Developmental Psychology, 46(2), 516-529.

Cassidy, J., \& Asher, S. R. (1992). Loneliness and peer relations in young children. Child Development, 63(2), 350-365. https:// doi.org/10.1111/j.1467-8624.1992.tb01632.x.

Cavanaugh, A. M., \& Buehler, C. (2016). Adolescent loneliness and social anxiety: The role of multiple sources of support. Journal of Social and Personal Relationships, 33(2), 149-170. https:// doi.org/10.1177/0265407514567837.

Chang, C.-Y. (2015). The effects of friendship and antipathy networks on adolescent attitude similarity. International Journal of Adolescence and Youth, 20(4), 407-428. https://doi. org/10.1080/02673843.2015.1015038.

Chorpita, B. F., Moffitt, C. E., \& Gray, J. (2005) Psychometric properties of the Revised Child Anxiety and Depression Scale in a clinical sample. Behaviour Research and Therapy, 43(3), 309-322. https://doi.org/10.1016/j.brat.2004.02.004.
Chorpita, B. F., Yim, L., Moffitt, C., Umemoto, L. A., \& Francis, S. E. (2000). Assessment of symptoms of DSM-IV anxiety and depression in children: A revised child anxiety and depression scale. Behaviour Research and Therapy, 38(8), 835-855. https ://doi.org/10.1016/S0005-7967(99)00130-8.

Ciarrochi, J., \& Heaven, P. C. L. (2008). Learned social hopelessness: The role of explanatory style in predicting social support during adolescence. Journal of Child Psychology and Psychiatry, 49(12), 1279-1286. https://doi.org/10.111 $1 /$ j.1469-7610.2008.01950.x.

Cillessen, A. H. N. (2009). Sociometric methods. In K. H. Rubin, W. M. Bukowski, \& B. P. Laursen (Eds.), Handbook of peer interactions, relationships, and groups (pp. 82-99). New York: Guilford Press.

Cillessen, A. H. N., \& Bellmore, A. D. (1999). Accuracy of social self-perceptions and peer competence in middle childhood. Merrill-Palmer Quarterly, 45(4), 650-676.

Cillessen, A. H. N., \& Bellmore, A. D. (2011). Social skills and social competence in interactions with peers. In P. K. Smith, \& C. H. Hart (Eds.), The Wiley-Blackwell handbook of childhood social development (pp. 393-412). Oxford: Wiley-Blackwell.

Cillessen, A. H. N., \& Marks, P. E. L. (2017). Methodological choices in peer nomination research: Methodological choices in peer nomination research. New Directions for Child and Adolescent Development, 2017(157), 21-44. https://doi. org/10.1002/cad.20206.

Cohen, S. (1992). Stress, social support, and disorder. In H. O. V. Veiel, \& U. Baumann (Eds.), The meaning and measurement of social support. New York: Hemisphere Press.

Coie, J. D., Dodge, K. A., \& Coppotelli, H. (1982) Dimensions and types of social status: A cross-age perspective. Developmental Psychology, 18(4), 557-570.

Cole, D. A., Nolen-Hoeksema, S., Girgus, J., \& Paul, G. (2006). Stress exposure and stress generation in child and adolescent depression: A latent trait-state-error approach to longitudinal analyses. Journal of Abnormal Psychology, 115(1), 40-51. https://doi.org/10.1037/0021-843X.115.1.40.

Costello, E. J., Pine, D. S., Hammen, C., March, J. S., Plotsky, P. M., \& Weissman, M. M. (2002). Development and natural history of mood disorders. Biological Psychiatry, 52(6), 529-542. https:// doi.org/10.1016/S0006-3223(02)01372-0.

Csardi, G., \& Nepusz, T. (2006). The igraph software package for complex network research. InterJournal, Complex Systems, 1695, $1-9$.

Cumming, G. (2014). The new statistics: Why and how. Psychological Science, 25(1), 7-29. https://doi.org/10.1177/0956797613 504966.

Danneel, S., Bijttebier, P., Bastin, M., Colpin, H., Van den Noortgate, W., \& Van Leeuwen, K. (2019). Loneliness, social anxiety, and depressive symptoms in adolescence: Examining their distinctiveness through factor analysis. Journal of Child and Family Studies. https://doi.org/10.1007/s10826-019-01354-3.

de Jong Gierveld, J., \& Kamphuls, F. (1985). The development of a Rasch-type loneliness scale. Applied Psychological Measurement, 9(3), 289-299. https://doi.org/10.1177/014662168500900 307.

de Jong Gierveld, J., \& van Tilburg, T. (1999). Living arrangements of older adults in the Netherlands and Italy: Coresidence values and behaviour and their consequences for loneliness. Journal of Cross-Cultural Gerontology, 14(1), 1-24.

de Jong Gierveld, J., van Tilburg, T., \& Dykstra, P. A. (2006). Loneliness and social isolation. In A. L. Vangelisti \& D. Perlman (Eds.), Cambridge handbook of personal relationships (pp. 485-500). Cambridge: Cambridge University Press.

Dodge, K. A. (1993). Social-cognitive mechanisms in the development of conduct disorder and depression. Annual Review of 
Psychology, 44(1), 559-584. https://doi.org/10.1146/annur ev.ps.44.020193.003015.

Dozois, D. J. A., \& Beck, A. T. (2008). Cognitive schemas, beliefs and assumptions. In K. S. Dobson, D. J. A. Dozois (Eds.), Risk factors in depression (pp. 121-143). Amsterdam: Elsevier.

Duck, S., Pond, K., \& Leatham, G. (1994). Loneliness and the evaluation of relational events. Journal of Social and Personal Relationships, 11(2), 253-276. https://doi.org/10.1177/0265407594 112006.

Duffy, A. L., Gardner, A. A., \& Zimmer-Gembeck, M. J. (2020). Peer rejection and dislike. In S. Hupp \& J. Jewell (Eds.), The encyclopedia of child and adolescent development (1st ed., p. 191). New York: Wiley. https://doi.org/10.1002/9781119171492.

Duke, L. H. (2017). The importance of social ties in mental health. Mental Health and Social Inclusion, 21(5), 264-270. https://doi. org/10.1108/MHSI-07-2017-0029.

Dykstra, P. A., \& de Jong Gierveld, J. (2004). Gender and marital-history differences in emotional and social loneliness among Dutch older adults. Canadian Journal on Aging/La revue canadienne $d u$ vieillissement, 23(02), 141-155. https://doi.org/10.1353/ cja.2004.0018.

Eccles, A. M., \& Qualter, P. (2020). Review: Alleviating loneliness in young people - a meta-analysis of interventions. Child and Adolescent Mental Health. https://doi.org/10.1111/camh.12389.

Egidi, G., Shintel, H., Nusbaum, H., \& Cacioppo, J. T. (2008). Social isolation and neural correlates of attention control. Presented at the 20th Annual Meeting of the Association for Psychological Science, Chicago, IL.

Engels, M. C., Colpin, H., Van Leeuwen, K., Bijttebier, P., Den Noortgate, W. V., \& Claes, S. (2017). School engagement trajectories in adolescence: The role of peer likeability and popularity. Journal of School Psychology, 64, 61-75. https://doi.org/10.1016/j. jsp.2017.04.006.

Erzen, E., \& Çikrikci, Ö. (2018). The effect of loneliness on depression: A meta-analysis. International Journal of Social Psychiatry, 64(5), 427-435. https://doi.org/10.1177/0020764018776349.

European Commission. (2018). Loneliness-an unequally shared burden in Europe. https://ec.europa.eu/jrc/sites/jrcsh/files/fairn ess_pb2018_loneliness_jrc_i1.pdf. Accessed 24 October 2020.

Ferrari, A. J., Charlson, F. J., Norman, R. E., Patten, S. B., Freedman, G., \& Murray, C. J. L. (2013). Burden of depressive disorders by country, sex, age, and year: Findings from the global burden of disease study 2010. PLoS Medicine ,10(11), e1001547. https://doi.org/10.1371/journal.pmed.1001547.

Freeman, L. C. (1978). Centrality in social networks conceptual clarification. Social Networks, 1(3), 215-239. https://doi. org/10.1016/0378-8733(78)90021-7.

Gable, S. L. (2006). Approach and avoidance social motives and goals. Journal of Personality, 74(1), 175-222. https://doi.org/ 10.1111/j.1467-6494.2005.00373.x.

Gommans, R., \& Cillessen, A. H. N. (2015) Nominating under constraints: A systematic comparison of unlimited and limited peer nomination methodologies in elementary school. International Journal of Behavioral Development, 39(1), 77-86. https://doi.org/10.1177/0165025414551761.

Grygiel, P., Humenny, G., \& Rębisz, S. (2019). Using the de Jong Gierveld Loneliness Scale with early adolescents: Factor structure, reliability, stability, and external validity. Assessment, 26(2), 151-165. https://doi.org/10.1177/1073191116682298.

Grygiel, P., Humenny, G., Rębisz, S., Świtaj, P., \& Sikorska-Grygiel, J. (2013) Validating the Polish adaptation of the De JongGierveld Loneliness Scale. European Journal of Psychological Assessment, 29(2), 129-139.

Hayvren, M., \& Hymel, S. (1984). Ethical issues in sociometric testing: Impact of sociometric measures on interaction behavior.
Developmental Psychology, 20(5), 844-849. https://doi. org/10.1037/0012-1649.20.5.844.

Heinrich, L. M., \& Gullone, E. (2006) The clinical significance of loneliness: A literature review. Clinical Psychology Review, 26(6), 695-718. https://doi.org/10.1016/j.cpr.2006.04.002.

Hoffman, K. B., Cole, D. A., Martin, J. M., Tram, J., \& Seroczynski, A. D. (2000). Are the discrepancies between self- and others' appraisals of competence predictive or reflective of depressive symptoms in children and adolescents: A longitudinal study, part II. Journal of Abnormal Psychology, 109(4), 651-662. https://doi.org/10.1037/0021-843X.109.4.651.

Iverson, A. M., \& Iverson, G. L. (1998). Children's long-term reactions to participating in sociometric assessment. Psychology in the Schools, 33(2), 103-112. https://doi.org/10.1002/ (SICI) 1520-6807(199604)33:2<103::AID-PITS2>3.0.CO;2-S.

Jackson, D. L. (2003). Revisiting sample size and number of parameter estimates: Some support for the n:q hypothesis. Structural Equation Modeling: A Multidisciplinary Journal, 10(1), 128-141. https://doi.org/10.1207/S15328007SEM1001_6.

Jobe-Shields, L., Cohen, R., \& Parra, G. R. (2011). Patterns of change in children's loneliness: Trajectories from third through fifth grades. Merrill-Palmer Quarterly, 57(1), 25-47. https:// doi.org/10.2307/23098054.

Kline, R. B. (2011). Convergence of structural equation modeling and multilevel modeling. In The SAGE handbook of innovation in social research methods (pp. 562-589). London: SAGE Publications Ltd. https://doi.org/https://doi.org/10.4135/97814 46268261.n31

Ladd, G. W., \& Troop-Gordon, W. (2003). The role of chronic peer difficulties in the development of children's psychological adjustment problems. Child Development, 74(5), 1344-1367. https://doi.org/10.1111/1467-8624.00611.

Lasgaard, M., Goossens, L., \& Elklit, A. (2011). Loneliness, depressive symptomatology, and suicide ideation in adolescence: Cross-sectional and longitudinal analyses. Journal of Abnormal Child Psychology ,39(1), 137-150. https://doi. org/10.1007/s10802-010-9442-x.

Lindenberg, S. (2008) Social rationality, semi-modularity and goalframing: What is it all about? Analyse \& Kritik., 30(2), 669-687.

Lodder, G. M. A., Scholte, R. H. J., Goossens, L., Engels, R. C. M. E., \& Verhagen, M. (2016). Loneliness and the social monitoring system: Emotion recognition and eye gaze in a real-life conversation. British Journal of Psychology, 107(1), 135-153. https://doi. org/10.1111/bjop.12131.

London, B., Downey, G., Bonica, C., \& Paltin, I. (2007). Social causes and consequences of rejection sensitivity. Journal of Research on Adolescence, 17(3), 481-506. https://doi.org/10.11 11/j.1532-7795.2007.00531.x.

Masi, C. M., Chen, H. Y., Hawkley, L. C., \& Cacioppo, J. T. (2011) A meta-analysis of interventions to reduce loneliness. Personality and Social Psychology Review, 15(3), 219-266.

Matthews, T., Danese, A., Wertz, J., Odgers, C. L., Ambler, A., Moffitt, T. E., Arseneault, L. (2016). Social isolation, loneliness and depression in young adulthood: A behavioural genetic analysis. Social Psychiatry and Psychiatric Epidemiology. https://doi. org/10.1007/s00127-016-1178-7.

Mellor, D., Stokes, M., Firth, L., Hayashi, Y., \& Cummins, R. (2008). Need for belonging, relationship satisfaction, loneliness, and life satisfaction. Personality and Individual Differences, 45(3), 213-218. https://doi.org/10.1016/j.paid.2008.03.020.

Muthén, L. K., \& Muthén, B. O. (2017). Mplus. Statistical analysis with latent variables. User's guide (8th ed.). Los Angeles, CA: Muthén \& Muthén.

Nangle, D. W., Erdley, C. A., Newman, J. E., Mason, C. A., \& Carpenter, E. M. (2003). Popularity, friendship quantity, and friendship quality: Interactive influences on children's loneliness and 
depression. Journal of Clinical Child \& Adolescent Psychology, 32(4), 546-555. https://doi.org/10.1207/S15374424JCCP32 04_7.

Newcomb, A. F., Bukowski, W. M. (1983). Social impact and social preference as determinants of children's peer group status. Developmental Psychology, 19(6), 856-867. https://doi. org/10.1037/0012-1649.19.6.856.

Newton, S., Docter, S., Reddin, E., Merlin, T., \& Hiller, J. (2010). Depression in adolescents and young adults: Evidence review. Adelaide, AU: Adelaide Health Technology Assessment, University of Adelaide. https://www.adelaide.edu.au/ahta/pubs/ depression-in-adolescents-and-young-adults.pdf. Accessed 24 October 2020

Parker, J. G., \& Asher, S. R. (1993). Friendship and friendship quality in middle childhood: Links with peer group acceptance and feelings of loneliness and social dissatisfaction. Developmental Psychology, 29(4), 611-621. https://doi. org/10.1037/0012-1649.29.4.611.

Parkhurst, J. T., \& Asher, S. R. (1992). Peer rejection in middle school: Subgroup differences in behavior, loneliness, and interpersonal concerns. Developmental Psychology, 28(2), 231-241. https:// doi.org/10.1037/0012-1649.28.2.231.

Pedersen, S., Vitaro, F., Barker, E. D., \& Borge, A. I. H. (2007). The timing of middle-childhood peer rejection and friendship: Linking early behavior to early-adolescent adjustment. Child Development, 78(4), 1037-1051. https://doi.org/10.111 1/j.1467-8624.2007.01051.x.

Penning, M. J., Liu, G., \& Chou, P. H. B. (2014). Measuring loneliness among middle-aged and older adults: The UCLA and de Jong Gierveld loneliness scales. Social Indicators Research, 118(3), 1147-1166. https://doi.org/10.1007/s11205-013-0461-1.

Portillo, M., \& Fernández-Baena, J. (2019). Social self-perception in adolescents: Accuracy and bias in their perceptions of acceptance/rejection. Psicología Educativa, 26(1), 1-6. https://doi. org/10.5093/psed2019a12.

Preacher, K. J., \& Hayes, A. F. (2008). Asymptotic and resampling strategies for assessing and comparing indirect effects in multiple mediator models. Behavior Research Methods, 40(3), 879-891. https://doi.org/10.3758/BRM.40.3.879.

Putarek, V., \& Keresteš, G. (2016). Self-perceived popularity in early adolescence: Accuracy, associations with loneliness, and gender differences. Journal of Social and Personal Relationships, 33(2), 257-274. https://doi.org/10.1177/0265407515574465.

Rozin, P., Royzman, E. B. (2001). Negativity bias, negativity dominance, and contagion. Personality and Social Psychology Review, 5(4), 296-320. https://doi.org/10.1207/S15327957PSPR0504_2.

Rudolph, K. (2009). Interpersonal context of adolescent depression. In S. Nolen-Hoeksema \& L. M. Hilt (Eds.), Handbook of depression in adolescents (pp. 377-418). New York: Routledge/Taylor $\&$ Francis Group.

Sentse, M., Lindenberg, S., Omvlee, A., Ormel, J., \& Veenstra, R. (2010). Rejection and acceptance across contexts: Parents and peers as risks and buffers for early adolescent psychopathology. The TRAILS study. Journal of Abnormal Child Psychology, 38(1), 119-130. https://doi.org/10.1007/s10802-009-9351-z.

Skoczeń, I., Rogoza, R., Rogoza, M., Ebesutani, C., \& Chorpita, B. (2019). Structure, reliability, measurement stability, and construct validity of the Polish version of the Revised Child Anxiety and Depression Scale. Assessment, 26(8), 1492-1503. https ://doi.org/10.1177/1073191117711019.

Sobel, M. E. (1982). Asymptotic confidence intervals for indirect effects in structural equation models. Sociological Methodology, 13, 290. https://doi.org/10.2307/270723.

Solmi, M., Veronese, N., Galvano, D., Favaro, A., Ostinelli, E. G., \& Noventa, V. (2020). Factors associated with loneliness: An umbrella review of observational studies. Journal of Affective Disorders. https://doi.org/10.1016/j.jad.2020.03.075.

Stebbins, R. A. (2008). A theory of the definition of the situation*. Canadian Review of Sociology/Revue canadienne de sociologie, 4(3), 148-164. https://doi.org/10.1111/j.1755-618X.1967. tb01209.x.

Stout, W. (1987). A nonparametric approach for assessing latent trait unidimensionality. Psychometrika, 52(4), 589-617. https://doi. org/10.1007/BF02294821.

Streiner, D. L. (2005). Finding our way: An introduction to path analysis. The Canadian Journal of Psychiatry, 50(2), 115-122. https ://doi.org/10.1177/070674370505000207.

Streiner, D. L. (2006). Building a better model: An introduction to structural equation modelling. The Canadian Journal of Psychiatry, 51(5), 317-324. https://doi.org/10.1177/0706743706 05100507.

Sweeting, H., West, P., Young, R., \& Kelly, S. (2011). Dimensions of adolescent subjective social status within the school community: Description and correlates. Journal of Adolescence, 34(3), 493-504. https://doi.org/10.1016/j.adolescence.2010.06.001.

Świtaj, P., Grygiel, P., Chrostek, A., Wciórka, J., \& Anczewska, M. (2018). Investigating the roles of loneliness and clinician- and self-rated depressive symptoms in predicting the subjective quality of life among people with psychosis. Social Psychiatry and Psychiatric Epidemiology, 53(2), 183-193. https://doi. org/10.1007/s00127-017-1470-1.

Taylor, S. E. (1991). Asymmetrical effects of positive and negative events: The mobilization-minimization hypothesis. Psychological Bulletin, 110(1), 67-85. https://doi. org/10.1037/0033-2909.110.1.67.

Thapar, A., Collishaw, S., Pine, D. S., \& Thapar, A. K. (2012). Depression in adolescence. The Lancet, 379(9820), 1056-1067. https:// doi.org/10.1016/S0140-6736(11)60871-4.

Toner, M. A., \& Heaven, P. C. L. (2005). Peer-social attributional predictors of socio-emotional adjustment in early adolescence: A two-year longitudinal study. Personality and Individual Differences, 38(3), 579-590. https://doi.org/10.1016/j. paid.2004.05.013.

van den Berg, Y. H. M., \& Gommans, R. (2017). Computer-based methods for collecting peer nomination data: Utility, practice, and empirical support: Computer-based methods for collecting peer nomination data. New Directions for Child and Adolescent Development, 2017(157), 61-73. https://doi.org/10.1002/ cad.20207.

van Roekel, E., Ha, T., Verhagen, M., Kuntsche, E., Scholte, R. H. J., Engels, R. C. M. E. (2015). Social stress in early adolescents' daily lives: Associations with affect and loneliness. Journal of Adolescence, 45, 274-283. https://doi.org/10.1016/j.adolescenc e.2015.10.012.

Vandell, D. L., \& Hembree, S. E. (1994). Peer social status and friendship: Independent contributors to children's social and academic adjustment. Merrill-Palmer Quarterly, 40(4), 461-477.

Vanhalst, J., Gibb, B. E., Prinstein, M. J. (2015). Lonely adolescents exhibit heightened sensitivity for facial cues of emotion. Cognition and Emotion. https://doi.org/10.1080/02699931.2015.10924 20.

Vanhalst, J., Klimstra, T. A., Luyckx, K., Scholte, R. H. J., Engels, R. C. M. E., Goossens, L. (2012). The interplay of loneliness and depressive symptoms across adolescence: Exploring the role of personality traits. Journal of Youth and Adolescence, 41(6), 776-787. https://doi.org/10.1007/s10964-011-9726-7.

Vanhalst, J., Luyckx, K., Scholte, R. H. J., Engels, R. C. M. E., Goossens, L. (2013). Low self-esteem as a risk factor for loneliness in adolescence: Perceived—but not actual—social acceptance as an underlying mechanism. Journal of Abnormal Child Psychology, 41(7), 1067-1081. https://doi.org/10.1007/s10802-013-9751-y. 
Vanhalst, J., Luyckx, K., Teppers, E., \& Goossens, L. (2012). Disentangling the longitudinal relation between loneliness and depressive symptoms: Prospective effects and the intervening role of coping. Journal of Social and Clinical Psychology, 31(8), 810-834. https ://doi.org/10.1521/jscp.2012.31.8.810.

Veenstra R., Dijkstra, J. K., Steglich, C., \& Van Zalk, M. H. W. (2013). Network-behavior dynamics. Journal of Research on Adolescence, 23(3), 399-412.

Verhagen, M., Lodder, G. M. A., \& Baumeister, R. F. (2018). Unmet belongingness needs but not high belongingness needs alone predict adverse well-being: A response surface modeling approach. Journal of Personality, 86(3), 498-507. https://doi.org/10.1111/ jopy. 12331.

Véronneau, M.-H., Vitaro, F., Brendgen, M., Dishion, T. J., \& Tremblay, R. E. (2010). Transactional analysis of the reciprocal links between peer experiences and academic achievement from middle childhood to early adolescence. Developmental Psychology, 46(4), 773-790. https://doi.org/10.1037/a0019816.

Wentzel, K. R., Battle, A., Russell, S. L., \& Looney, L. B. (2010). Social supports from teachers and peers as predictors of academic and social motivation. Contemporary Educational Psychology, 35(3), 193-202. https://doi.org/10.1016/j.cedps ych.2010.03.002.

Woodhouse, S. S., Dykas, M. J., \& Cassidy, J. (2012). Loneliness and peer relations in adolescence: Loneliness in adolescence. Social Development, 21(2), 273-293. https://doi.org/10.111 1/j.1467-9507.2011.00611.x.
World Health Organization. (1992). International statistical classification of diseases, tenth revision (icd-10). World Health Organization.

World Health Organization. (2020). Depression. https://www.who.int/ news-room/fact-sheets/detail/depression. Accessed 24 October 2020.

Yap, B. M., Lawrence, A. K., Rapee, M. R., Cardamone-Breen, C. M., Green, J., \& Jorm, F. A. (2017). Partners in parenting: A multilevel web-based approach to support parents in prevention and early intervention for adolescent depression and anxiety. JMIR Mental Health, 4(4), e59. https://doi.org/10.2196/mental.8492.

Zimmer-Gembeck, M. J., Hunter, T. A., \& Pronk, R. (2007). A model of behaviors, peer relations and depression: Perceived social acceptance as a mediator and the divergence of perceptions. Journal of Social and Clinical Psychology, 26(3), 273-302. https ://doi.org/10.1521/jscp.2007.26.3.273.

Zimmer-Gembeck, M. J., Hunter, T. A., Waters, A. M., \& Pronk, R. (2009). Depression as a longitudinal outcome and antecedent of preadolescents' peer relationships and peer-relevant cognition. Development and Psychopathology, 21(02), 555. https:// doi.org/10.1017/S0954579409000303.

Publisher's Note Springer Nature remains neutral with regard to jurisdictional claims in published maps and institutional affiliations. 